\section{Correspondence on 'EULAR recommendations for a core data set for pregnancy registries in rheumatology'}

Although recommendations to manage women with rheumatoid arthritis (RA) during the reproductive phase have been established, there is further need for evidence-based information on drug treatment and safety during pregnancy. ${ }^{1}$ Registries are excellent data sources to address remaining questions. Therefore, a minimal core data set for registers studying pregnancy in rheumatology has been developed recently by an EULAR task force. $^{2}$ We evaluated the feasibility of data collection according to this minimal core data set in the daily clinical management of pregnant women with RA within the rheumatology department of the University Hospital of Leuven (UHL).

We performed a retrospective patient chart study in a population of 1072 patients (360 men and 712 women) with RA with a planned rheumatology outpatient visit at UHL between November 2019 and November 2020. Women were included if they were diagnosed with RA before getting pregnant, had a recorded pregnancy during the past 5 years and were born later than or in 1970 . We recorded a total of 30 pregnancies in 21 women. Data from these patients' files were collected based on the proposed minimal core data set of 51 items and split into three main categories: 'maternal information' (18 items), 'pregnancy' (25 items) and 'treatment' (eight items). Data were captured during three phases: 'before', 'during' and 'after' pregnancy. The 'before' phase started 12 months before conception until last visit before conception. Conception date, if not recorded, was estimated counting back 9 months from the date of delivery. The 'during' phase started from the first visit during the current pregnancy until the last visit before delivery. Finally, the 'after' phase consisted of the first visit after delivery. Additionally, we considered the first 'baseline' visit to the UHL rheumatology department to collect more extensive health data, since gynaecological and pregnancy history is typically collected during the patient's first visit.

Figure 1 shows the results of our study per core item. We evaluated to what extent the proposed minimal core data set for pregnant women with RA was collected in daily practice. Treatment-related and maternal information was registered adequately. However, certain non-disease-specific outcomes belonging to the 'maternal information' category might be more applicable to other rheumatic and musculoskeletal diseases (RMDs) than to RA. For example, antiphospholipid syndrome is more associated with systematic lupus erythematosus than with other RMDs, possibly leading to only sporadic registration. Information on pregnancy outcome was less extensively registered in the rheumatology file at UHL. Of course, the set of core data is conceived to conduct prospective studies and to standardise registers on pregnant women with RMDs in contrast to this daily practice chart review. The rheumatology file was not specifically designed to collect such information, partly because it is integrated in a broader electronic medical file containing also information from other departments in separate files. Missing data could be present in those other files as well, but that was not part of the scope of this analysis. Nevertheless, collection and accessibility of these data should then be harmonised to improve data registration. A limitation of the proposed minimal core data set is that the visit after pregnancy should be within 4 weeks. In only five pregnancies, patients could attain their follow-up consultation within this period. This short postpartum period
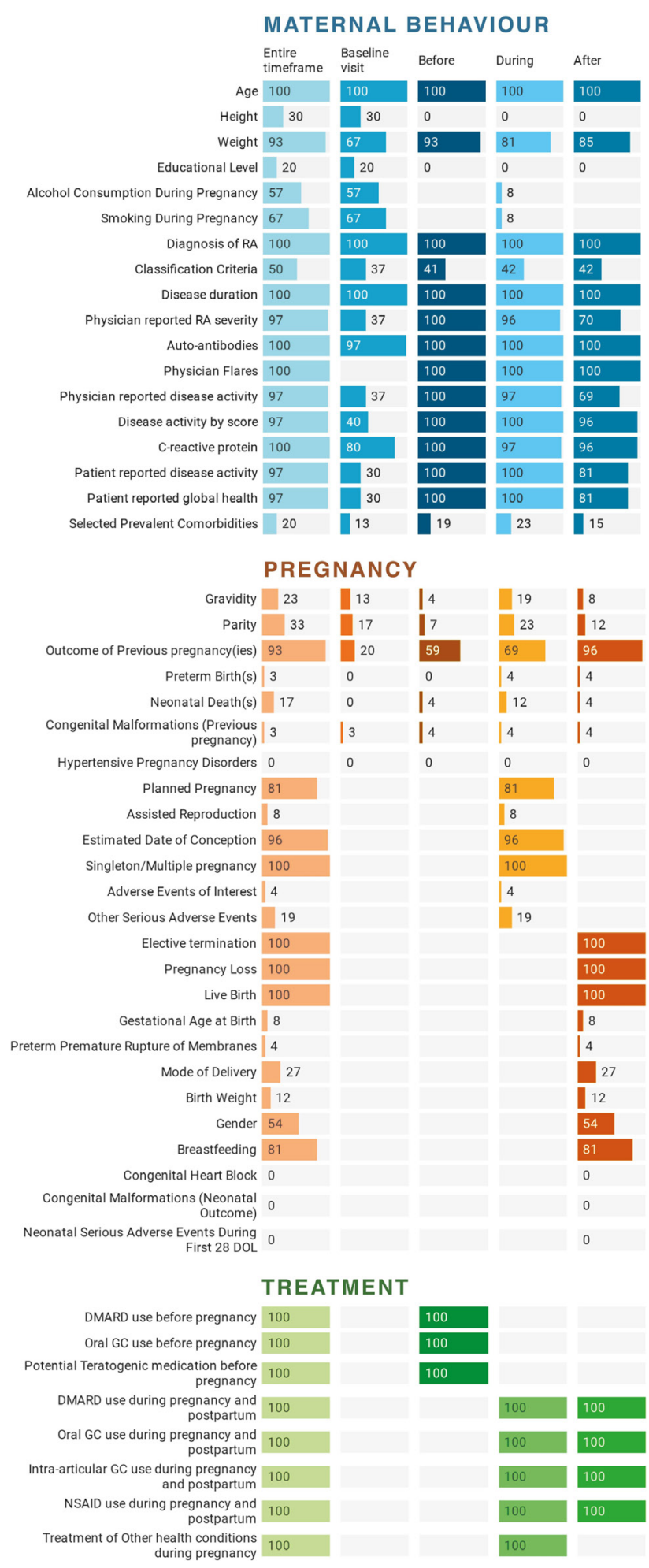

Figure 1 Proportions (\%) represent the extent to which patient charts contain the key data as required per core item, determined per pregnancy. All items concerning 'treatment' were always registered. Certain aspects in the category 'maternal information' were consistently collected, while other data were often missing. For example, smoking behaviour and alcohol consumption were seldomly recorded during pregnancy. Data collection from the third category, 'pregnancy', showed less concordance with the core data set compared with the other two. $\mathrm{bp}$, before pregnancy; DMARD, disease modifying anti rheumatic drug; DOL, days of life; DP, during pregnancy; GC, glucocorticoid; NSAID, non-steroidal anti inflammatory drug; PP, post partum; RA, rheumatoid arthritis. 
might lead to loss of developmental data on the new-born if strictly followed. However, overall, the proposed minimal core data set seems feasible in daily practice.

Diederik De Cock ๑,${ }^{1}$ Isaline Soenen, ${ }^{1}$ Delphine Bertrand, ${ }^{1}$ Sofia Pazmino $\odot,{ }^{1}$ Veerle Stouten, ${ }^{1}$ Rene Westhovens $\odot{ }^{1,2}$ Patrick Verschueren ${ }^{1,2}$

${ }^{1}$ Department of Development and Regeneration, Skeletal Biology and Engineering Research Center, KU Leuven, Leuven, Belgium

${ }^{2}$ Rheumatology, University Hospitals of Leuven, University Hospitals of Leuven, Leuven, Belgium

Correspondence to Dr Diederik De Cock, Department of Development and Regeneration, Skeletal Biology and Engineering Research Center, KU Leuven, Leuven, Belgium; diederik.decock@kuleuven.be

Twitter Diederik De Cock @DiederikDeCock and Sofia Pazmino @sophie_33pl

Contributors DDC and PV conceived of the presented idea. IS performed the data collection. All authors discussed the results and contributed to the final manuscript.

Funding The authors have not declared a specific grant for this research from any funding agency in the public, commercial or not-for-profit sectors.

Competing interests None declared.

Patient and public involvement Patients and/or the public were not involved in the design, or conduct, or reporting, or dissemination plans of this research.

Patient consent for publication Not required.

Provenance and peer review Not commissioned; internally peer reviewed. (c) Author(s) (or their employer(s)) 2020. No commercial re-use. See rights and permissions. Published by BMJ.

\section{(D) Check for updates}

To cite De Cock D, Soenen I, Bertrand D, et al. Ann Rheum Dis Epub ahead of print: [please include Day Month Year]. doi:10.1136/annrheumdis-2020-219457

Received 5 November 2020

Accepted 7 November 2020

\section{Linked}

https://doi.org/10.1136/annrheumdis-2020-219478

Ann Rheum Dis 2020;0:1-2. doi:10.1136/annrheumdis-2020-219457

\section{ORCID iDs}

Diederik De Cock http://orcid.org/0000-0002-5656-6236

Sofia Pazmino http://orcid.org/0000-0001-8579-6914

Rene Westhovens http://orcid.org/0000-0002-3432-3073

\section{REFERENCES}

1 Götestam Skorpen C, Hoeltzenbein M, Tincani A, et al. The EULAR points to consider for use of antirheumatic drugs before pregnancy, and during pregnancy and lactation. Ann Rheum Dis 2016;75:795-810.

2 Meissner Y, Fischer-Betz R, Andreoli L, et al. EULAR recommendations for a core data set for pregnancy registries in rheumatology. Ann Rheum Dis 2020:annrheumdis-2020-218356. 